\title{
Hypertension, diabetes mellitus, and cerebrovascular disease predispose to a more severe outcome of COVID-19
}

Kamleshun Ramphul ${ }^{1}$, Petras Lohana², Yogeshwaree Ramphul ${ }^{3}$, Yun Park ${ }^{4}$, Stephanie Mejias ${ }^{5}$, Balkiranjit Kaur Dhillon ${ }^{6}$, Shaheen Sombans ${ }^{7}$, Renuka Verma ${ }^{8}$

\author{
${ }^{1}$ Department of Pediatrics, Shanghai Xin Hua Hospital, Shanghai Jiao Tong University, \\ School of Medicine, Shanghai, China \\ 2Department of Medicine, Liaquat University of Medical and Health Sciences \\ Hospital, Jamshroo, Pakistan \\ ${ }^{3}$ Department of Medicine, Sir Seewoosagur Ramgoolam National Hospital, \\ Pamplemousses, Mauritius \\ ${ }^{4}$ Department of Orthodontics, Affiliation: Shanghai Jiao Tong University, School of \\ Medicine, Shanghai, China \\ ${ }^{5}$ Department of Medicine, University Iberoamericana UNIBE, School of Medicine, \\ Santo Domingo, Dominican Republic \\ ${ }^{6}$ Department of Medicine, Baba Farid University of Health Sciences, Punjab Medical, \\ India \\ ${ }^{7}$ Department of Medicine, Bharati Vidyapeeth University Medical College and \\ Hospital, Pune, India \\ ${ }^{8}$ Department of Medicine, Guru Gobind Singh Medical College, Punjab, India
}

Submitted: 18 November 2020

Accepted: 7 January 2021

Arch Med Sci Atheroscler Dis 2021; 6: e30-e39

DOI: https://doi.org/10.5114/amsad.2021.105255

Copyright (c) 2021 Termedia \& Banach

\section{Abstract}

Introduction: The world is currently facing the pandemic of severe acute respiratory syndrome coronavirus 2 (SARS-CoV-2). The total number of cases of coronavirus disease 2019 (COVID-19) is rising daily and no vaccine has yet been approved. While the pathophysiology behind the virus is still being studied, many possible several risk factors using small sample sizes have been found.

Material and methods: We conducted a pooled analysis using several databases such as Medline, Scopus, Wangfang, Web of Science, Research Square, medrxiv, and Google Scholar to identify studies reporting severe and non-severe groups of COVID-19 patients. The odds ratios as well as the $95 \%$ confidence intervals for hypertension, diabetes, and cerebrovascular disease leading to severe COVID-19 were calculated using R-software.

Results: Fifty-three articles were used for our analysis and they involved 30,935 confirmed cases of COVID-19 from several countries across the world. The odds ratio for severe COVID-19 in hypertensive patients, diabetics, and patients with a history of cerebrovascular disease was 2.58 (95\% confidence interval (Cl): 2.16-3.08, from 53 studies), 2.17 (95\% Cl: 1.72-2.74, from 44 studies), and 2.63 (95\% Cl: $1.80-3.85$, from 25 studies), respectively. Conclusions: Our analysis confirms that patients with hypertension, diabetes, or cerebrovascular disease are at a higher risk of a severe outcome of COVID-19. It is thus vital for physicians to identify the main risk factors for a severe outcome of this disease.

Key words: hypertension, diabetes, cerebrovascular disease, stroke, severity, COVID-19, SARS-CoV-2, coronavirus 2019, meta-analysis, pooled analysis.

\author{
Corresponding author: \\ Dr. Shaheen Sombans \\ Department of Medicine \\ Bharati Vidyapeeth \\ University Medical \\ College and Hospital \\ Medical College Road \\ Pune - Satara Rd \\ Dhankawadi, Pune \\ Maharashtra 411043 \\ India \\ Phone: +9193737 28706 \\ E-mail: drshaheensombans@ \\ gmail.com
}




\section{Introduction}

In December 2019, several patients in Wuhan, China, were admitted with symptoms of "pneumonia of unknown etiology". Over the next few days, the Chinese Centre for Disease Control and Prevention (CDC) started to investigate the possible causes of these new and strange presentations. A new virus was finally identified and found to belong to the family of coronavirus (CoV) which also included severe acute respiratory syndrome coronavirus (SARS-CoV), discovered in 2002, and the Middle East respiratory syndrome coronavirus (MERS-CoV) which appeared in 2012 [1-3].

The virus was called severe acute respiratory syndrome Coronavirus 2 (SARS-CoV-2) and the disease it can cause was called coronavirus disease 2019 (COVID-19) [1]. As SARS-CoV-2 continued to spread over China and over different countries, the World Health Organization declared it as a pandemic. Almost a year later, it has infected about 85,892,625 people causing 1,857,399 deaths worldwide $[1,3,4]$. Since many countries have limited health care resources and intensive care units [3], many researchers studied early data to find possible risk factors that can lead to a more severe outcome of this virus [1, 5-13]. Analysis of SARS-COV-2 showed that the virus engages the angiotensin-converting enzyme 2 (ACE2) as a receptor to penetrate human cells [14]. The enzyme is present in multiple systems including the cardiovascular system. Diabetics have marked hyperglycemia which leads to inflammatory as well as coagulation imbalance [15], which potentiates the replication of the virus [16]. Hypertension and diabetes are also the two most important risk factors among patients with cerebrovascular disease. COVID-19 offers hypercoagulable and possible hypoxic states in some patients which could lead to more severe outcomes in patients with a prior history of cerebrovascular disease [17]. The severity of these three risk factors for the progress of COVID-19 patients was tested and confirmed using limited population groups during the first 4 months of the pandemic $[12,18,19]$. We hereby sought to expand and strengthen the understanding and risks using a larger population sample via a pooled analysis.

\section{Material and methods}

We used the guidelines set up by Preferred Reporting Items for Systematic Reviews and Meta-Analyses (PRISMA) to conduct a meta-analysis [20] (Figure 1). Our search team consisted of two groups. Each group first independently searched Medline, Scopus, Wangfang database, Web of Science, Research Square, medrxiv, and Google Scholar databases using the keywords "COVID-19", "coronavirus 2019", "2019-nCoV", "SARS-CoV-2", "hypertension", "diabetes", "diabetes mellitus", "cerebrovascular disease", and "stroke". Articles published between $1^{\text {st }}$ December 2019 and $15^{\text {th }}$ October 2020 were included in our selection. We were able to evaluate studies published in English, French, Chinese, and Spanish.

Studies needed to report two groups: one severe and one non-severe. Based on previous studies [7, 12, 19, 21-26] and since there are multiple guideline protocols in different countries, severity

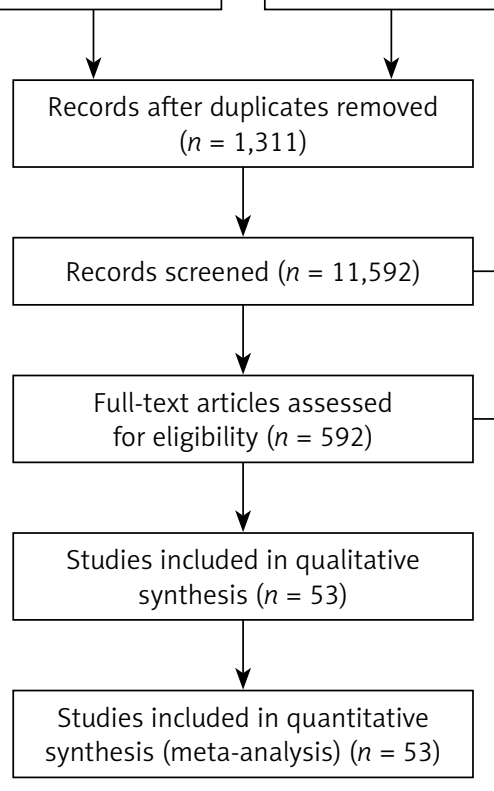

Figure 1. PRISMA flow-diagram 
was defined depending on either clinical presentation during their hospitalizations and laboratory findings [27-30], admission in intensive care unit [31], use of mechanical ventilation [32] or patients ranked using radiological findings [33]. The studies also had to include at least one of the three risk factors being studied by our team. We excluded studies that did not provide the raw table of data, case series, and case reports, meta-analyses and also had a very small sample size $(n<10)$.

The articles that met the initial search criteria were further assessed by their abstracts and full texts. Each researcher presented his/her search results and discussed it with his/her group [22, 34, 35]. Eventually, each group made its own list and discussed together with the team to draft a final inclusion list. Disagreements were resolved by a consensus from all the researchers involved.

\section{Statistical analysis}

Statistical analysis was performed using R software (version 4.0.3) (https://www.r-project.org/). We used the meta-package to study our data and a forest plot was also extrapolated [36]. The heterogeneity of our study was assessed via Higgins's $r^{2}$ test [37]. The fixed-effect model was applied if the $R^{2}$ was less than $50 \%$ and, the random-effect model was used for $l^{2}$ greater or equal to $50 \%$ for our study. The study was conducted in compliance with the Declaration of Helsinki and no ethical approval was required [38].

\section{Results}

Our initial search yielded 12,903 studies. They were first filtered off based on the title and abstract. Finally, 592 articles were reviewed for their full texts. We initially chose 77 studies and finally after careful evaluation and further discussions, 53 articles that matched our criteria of selection for hypertension [14, 27, 28, 30, 32, 33, 39-85], 44 articles that compared the presence of diabetes $[27,28,30,32,33,39-50,52-56,58-61,63$, $64,66-69,71-76,80,81,83-85]$, and 25 articles that reported the risk of patients with a prior cerebrovascular disease with a severe and non-severe outcome $[27,28,33,40,44-47,53,55,58-61,64$, $66,69,71,73-75,80-83$ ] were retained for our analysis.

\section{Hypertension}

A total of 7,031 patients formed the severe group and 23,904 patients formed the non-severe group in our selection. 2,514 severe patients also had a history of hypertension while 3,537 patients in the non-severe group had hypertension. The odds ratio for a hypertensive patient to have a severe outcome of COVID-19 was 2.58 (95\% confi- dence interval $(\mathrm{Cl}): 2.16-3.08$, heterogeneity: $1^{2}=$ $80 \%, p<0.01$ ) (Figure 2).

\section{Diabetes}

Our analysis found 6,327 severe cases and 22,071 non-severe cases amongst which 1,622 and 2,548 had a history of diabetes, respectively with an odds ratio of $2.17(95 \% \mathrm{Cl}: 1.72-2.74$, heterogeneity: $I^{2}=81 \%, p<0.01$ ) (Figure 3 ).

\section{Cerebrovascular disease}

Three hundred and seventy-three patients with a history of cerebrovascular disease developed a severe outcome of COVID-19 out of the 4,361 severe cases reported in total, compared to 481 of the 12,809 non-severe cases. Their odds ratio was estimated at $2.63(95 \% \mathrm{Cl}: 1.80-3.85$, heterogeneity: $l^{2}=63 \%, p<0.01$ ) (Figure 4).

\section{Discussion}

Our study provides an update on the impact of hypertension, diabetes, and cerebrovascular disease on the severity of COVID-19. It is one of the largest pooled analyses, to our knowledge, that includes these three risk factors. We used 53 studies that covered 30,935 confirmed cases of COVID-19 from several countries, classified as severe and non-severe ones.

The findings closely confirm early studies such as the study involving 2,552 patients conducted by Lippi et al. who found that the risk of severe COVID-19 is increased by almost 2.5 with a history of hypertension [12] while Del Sole et al. reported values of 2.24 among 2,794 patients [25]. Similar higher risks have been previously linked among patients with diabetes and cerebrovascular diseases. Aggarwal et al. studied previously published reports totaling 2,564 patients and found that the odds ratio of severity among diabetes was $2.60(95 \% \mathrm{Cl}: 1.96-3.45)$ [7]. Their team also published another early pooled analysis involving four studies and reported that patients with a prior history of cerebrovascular disease are at 2.5 higher risk of ending with a more severe outcome of COVID-19 [19].

While the increased risks of severity in patients with hypertension, diabetes, and cerebrovascular disease can now be statistically established, there are multiple theories and possible pathways concerning their pathophysiology. Huang et al. suggested that there may be an imbalance of various inflammatory cytokines in COVID-19 which may be more severe in hypertensive patients. Higher levels of multiple factors such as IL-6, IL-7, and granulocyte-macrophage colony-stimulating factor, and tumor necrosis factor $\alpha$ have also been reported to be involved in the various pathophys- 


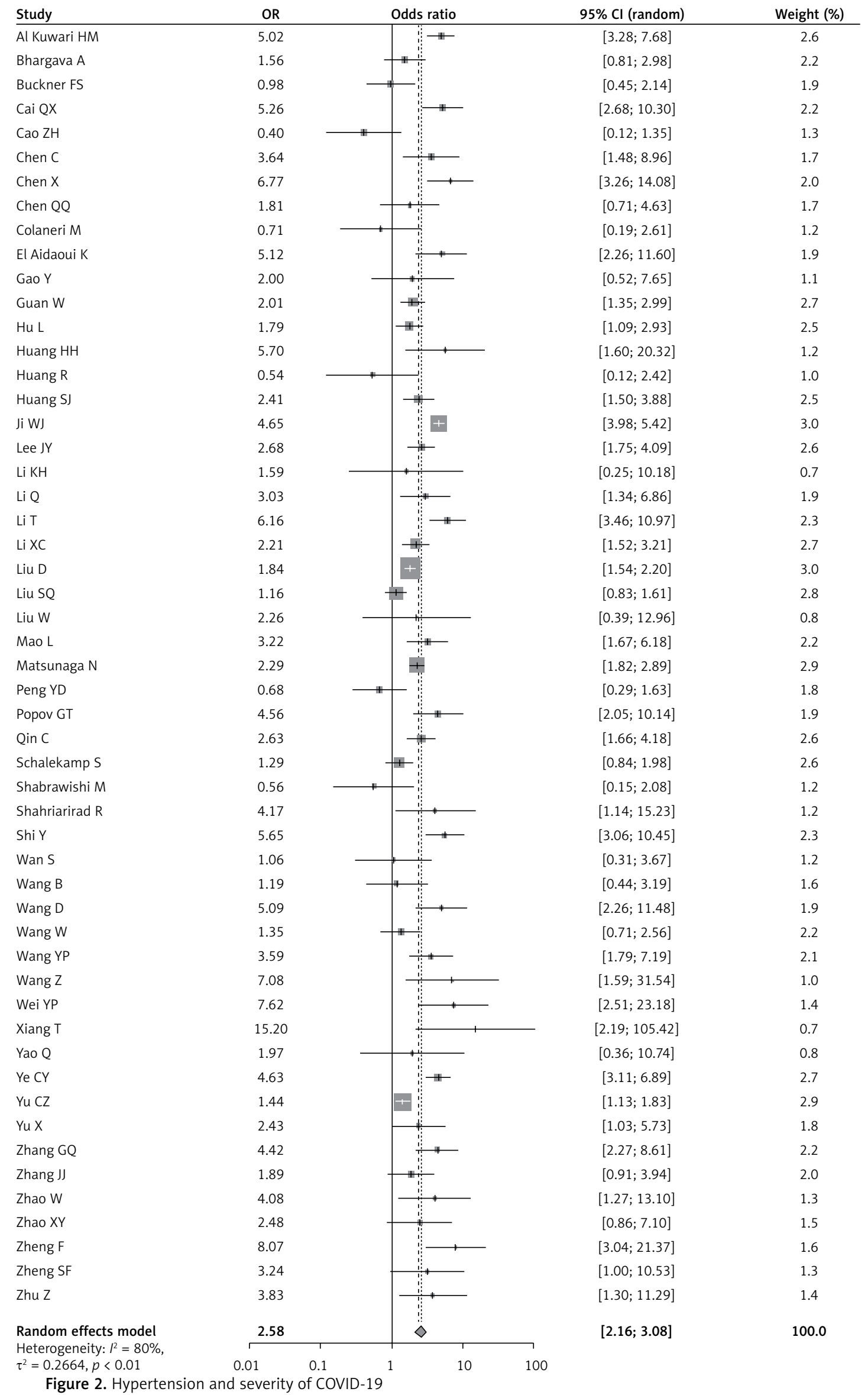




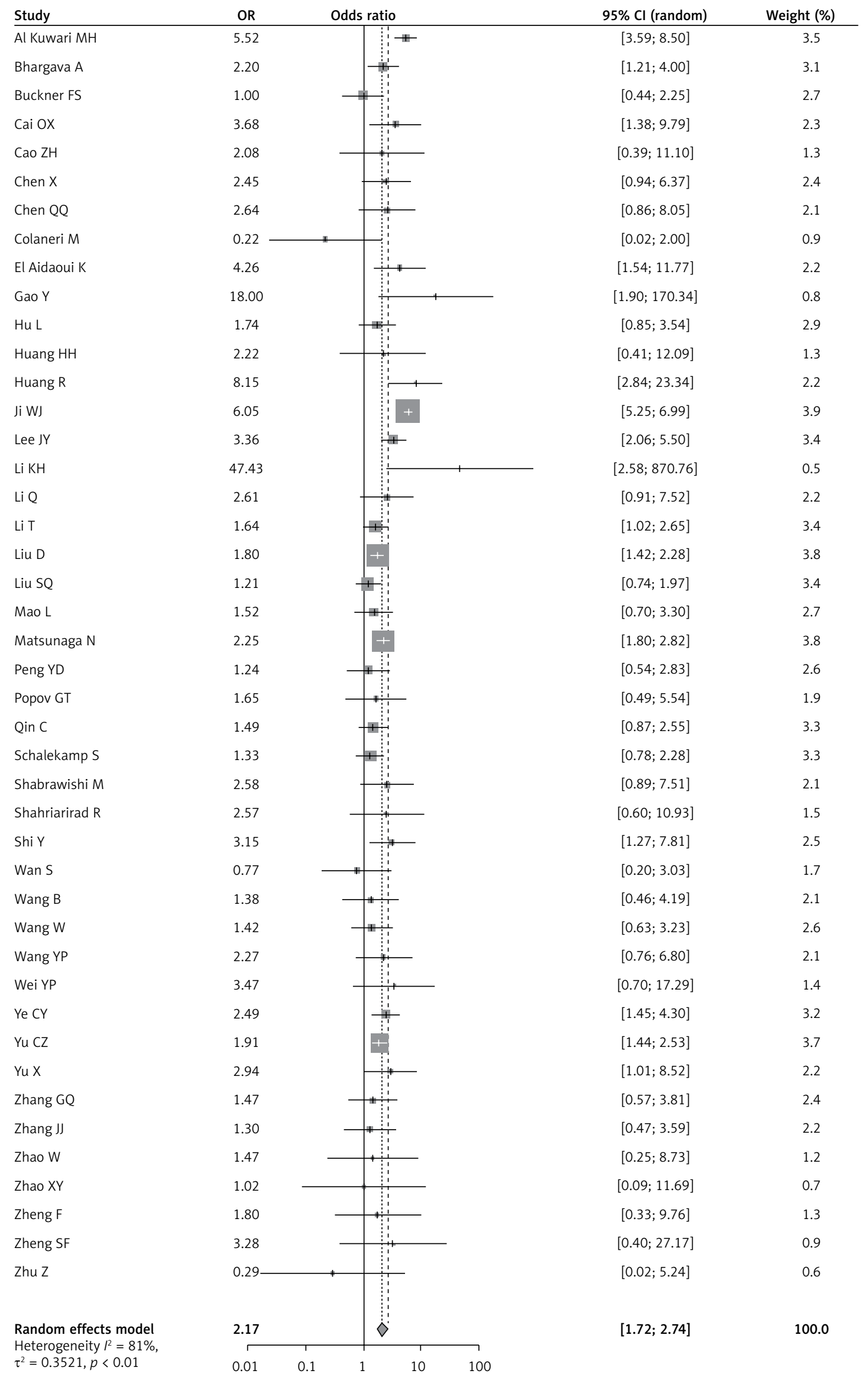

Figure 3. Diabetes and severity of COVID-19 


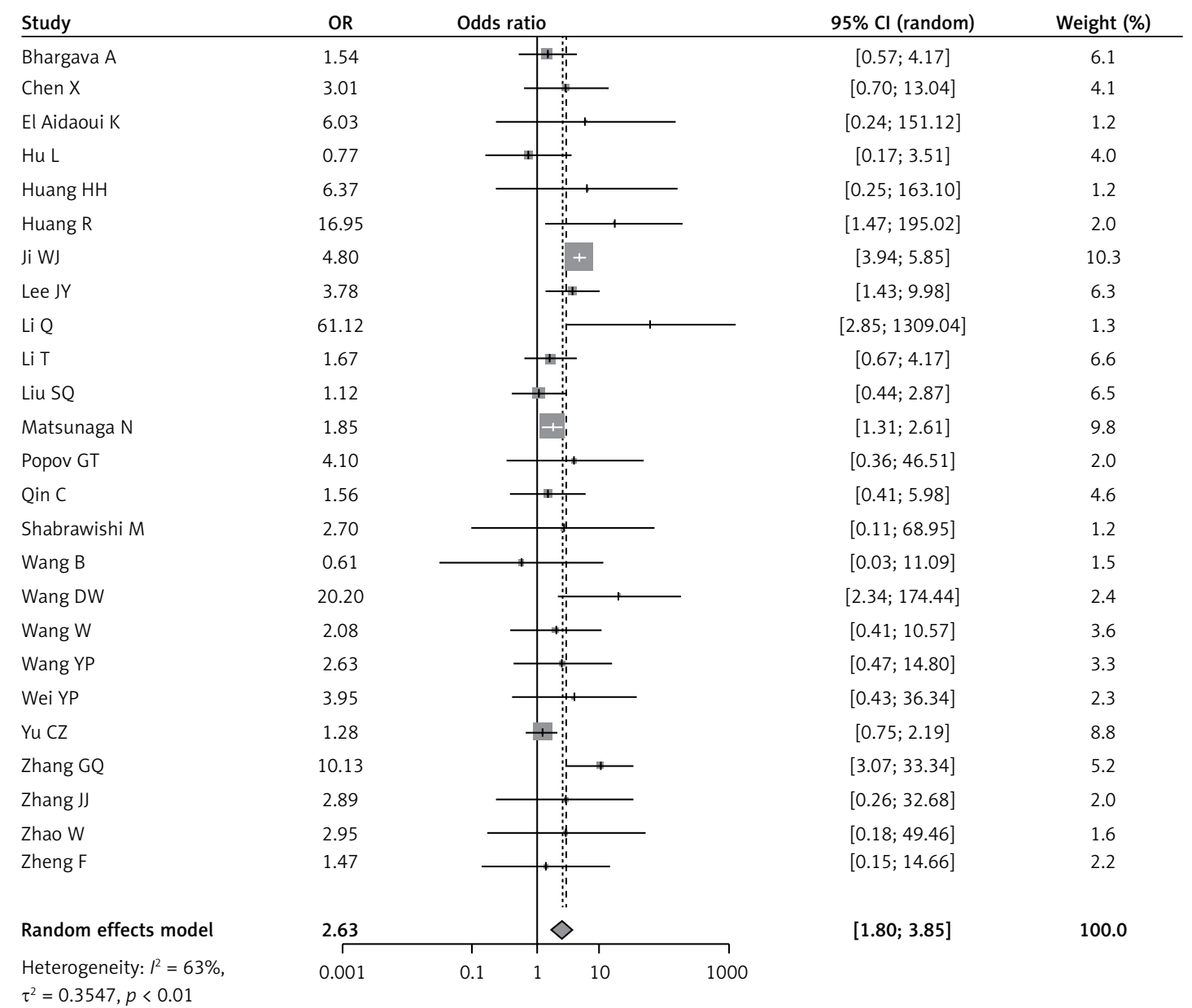

Figure 4. Cerebrovascular disease and severity of COVID-19

iologic pathways of hypertension. Their presence in COVID-19 patients can thus trigger a more severe outcome and also increase the risk of cytokine storms $[14,86,87]$. The possible link between the Renin-Angiotensin-Aldosterone System and COVID-19 has also been suggested [88]. The SARS-CoV-2 has an S spike protein (S-protein) that can bind to ACE2 receptors [89]. This allows the virus to enter the host cells. The viral and receptor complex is then endocytosed. This eventually leads to a lower number of the receptors and a higher level of Angiotensin II [90].

Several very similar pathways have also been hypothesized for diabetic patients. The higher levels of multiple pro-inflammatory conditions and the often co-accompanying obesity with diabetes can both lead to a more severe progression of COVID-19 [7, 91]. A study by Barron et al. found that there was also a higher risk of mortality in both type 1 and type 2 diabetics who were diagnosed with COVID-19 [92]. In their analysis, Wang et al. hypothesized that since the surfactant production and the vascular beds in diabetics are often affected, they typically have a poor pulmonary function [93]. They also hypothesized that the high sugar level and lower insulin level can affect mul- tiple innate immune responses that can lead to an impaired function of cells responsible for improving an immune protection in the alveoli and impact the proper formation of Th1 and Th2 cells. These make diabetics more prone to multiple pulmonary infections as they will have a slower and weaker response to combat them [93-101]. Further research should also be encouraged from hospitals to publish data on diabetics having different anti-diabetic treatments so that the relationship between antidiabetic treatments and severity of COVID-19 can also be explored in the future [102]. During the pre-COVID-19 era, several patient groups were also associated with higher risks and worse outcome of diabetic ketoacidosis [103]. Research comparing changes in severity and mortality in those specific patient groups can also help physicians prioritize their resources for a better clinical outcome.

The higher risks of severe COVID-19 in patients with a history of cerebrovascular disease have been linked with several possible pathophysiological pathways. Most stroke patients have underlying conditions such as diabetes and hypertension. They are also chronically using multiple drugs that can lead to multiple pathways in the pathogenesis of SARS-CoV-2. Several cases of new onset of stroke 
have also been reported in COVID-19 patients. A study by Merkler et al. found that COVID-19 had a 7.6 times higher risk of causing a new stroke than an influenza infection [104]. Fifi et al. warned that there are many new cases of stroke in young patients who initially presented with mild respiratory symptoms [105]. As COVID-19 is associated with multiple laboratory changes that can predispose previous and new patients with cerebrovascular insults, physicians need to be on the watch-out for neurological changes and symptoms [106-108].

Since COVID-19 is a new disease, the progress in understanding the impact and risk factors, as well as changes in management protocols of atrisk patients, have been done in a step-by-step manner based on findings from multiple cellular studies and pooled analyses. Initially, there were several arguments for and against the continued use of ACEI and ARBs among hypertensive patients, diabetics and also patients with a history of cerebrovascular disease [109, 110]. Both the European Society of Hypertension and the American Heart Association advised that these medications should not be discontinued as the benefits outweigh the risks [111]. Protocols involving the use and effects of corticosteroids among diabetics were also evaluated. High doses lead to a rise in blood glucose levels in up to $80 \%$ of diabetics who were COVID-19 positive and were associated with a higher mortality rate. With the higher severity of COVID-19, the use of anti-diabetic medications such as DPP4 Inhibitors and their effects are currently being studied [112-114]. While multiple changes have been established in the effective management of new cases of stroke in COVID-19 positive patients, guidelines for COVID-19 patients with a past history of cerebrovascular disease have followed the hypertensive and the diabetic protocols due to their close relationship in the pathophysiology [115-124].

In conclusion, our study provided a fresh view with a larger sample size on three main risk factors that can cause COVID-19 patients to have a severe outcome from the disease. We strongly believe that these preliminary reports can help physicians prioritize their limited healthcare resources and be prepared in advance for any severe outcome of the disease.

\section{Conflict of interest}

The authors declare no conflict of interest.

\section{References}

1. Ramphul K, Mejias SG. Coronavirus disease: a review of a new threat to public health. Cureus 2020; 12 e7276.

2. Cascella M, Rajnik M, Cuomo A, Dulebohn SC, Di Napoli R. Features, Evaluation, and Treatment of Corona- virus (COVID-19). StatPearls. Treasure Island (FL): StatPearls Publishing LLC.2020.

3. Kowlessur S, Ori B, Zimmet P, Tuomilehto J, Chitson P, Ramphul Y. Tackling the COVID-19 pandemic in paradise: the Mauritian experience. Lancet Diabetes Endocrinol 2020; 8: 878-9.

4. COVID-19 Coronavirus Pandemic 2020. Available from: https://www.worldometers.info/coronavirus/.

5. Adeli K, Lippi G, Henry BM, Sanchis-Gomar F, Mattiuzzi C. Updates on laboratory investigations in coronavirus disease 2019 (COVID-19). Clin Chem Labor Med 2020; 91: e2020030.

6. Cheruiyot I, Henry B, Lippi G, et al. Acute kidney injury is associated with worse prognosis in COVID-19 patients: a systematic review and meta-analysis. Acta Biomedica 2020; 91: e2020029.

7. Aggarwal G, Lippi G, Lavie CJ, Henry BM. Diabetes mellitus association with coronavirus disease 2019 (COVID-19) severity and mortality: a pooled analysis. J Diabetes 2020; 12: 851-5.

8. Henry B, Cheruiyot I, Vikse J, et al. Lymphopenia and neutrophilia at admission predicts severity and mortality in patients with COVID-19: a meta-analysis. Acta Biomedica 2020; 91: e2020008.

9. Lippi G, Henry BM, Sanchis-Gomar F. Red blood cell distribution is a significant predictor of severe illness in coronavirus disease 2019. Acta Haematol 2020: 1-5. doi: 10.1159/000510914.

10. Mattiuzzi C, Lippi G. Serum prealbumin values predict the severity of coronavirus disease 2019 (COVID-19). J Med Virol 2020. doi: 10.1002/jmv.26385.

11. Lippi G, Henry BM. Eosinophil count in severe coronavirus disease 2019. J Med Virol 2020; 113: 511-2.

12. Lippi G, Wong J, Henry BM. Hypertension in patients with coronavirus disease 2019 (COVID-19): a pooled analysis. Pol Arch Intern Med 2020; 130: 304-9.

13. Ramphul K, Mejias SG, Ramphul Y. Headache may not be linked with severity of coronavirus disease 2019 (COVID-19). World J Emergency Med 2020; 11: 274.

14. Huang S, Wang J, Liu F, et al. COVID-19 patients with hypertension have more severe disease: a multicenter retrospective observational study. Hypertens Res 2020; 43: 824-31.

15. Hussain A, Bhowmik B, do Vale Moreira NC. COVID-19 and diabetes: knowledge in progress. Diabetes Res Clin Practice 2020; 162: 108142.

16. Lim S, Bae JH, Kwon HS, Nauck MA. COVID-19 and diabetes mellitus: from pathophysiology to clinical management. Nature Rev Endocrinol 2021; 17: 11-30.

17. Fan H, Tang X. Influence of COVID-19 on cerebrovascular disease and its possible mechanism. Neuropsychiatr Dis Treat 2020; 16: 1359-67.

18. Aggarwal G, Lippi G, Lavie CJ, Henry BM, Sanchis-Gomar F. Diabetes mellitus association with coronavirus disease 2019 (COVID-19) severity and mortality: a pooled analysis. J Diabetes 2020; 12: 851-5.

19. Aggarwal G, Lippi G, Michael Henry B. Cerebrovascular disease is associated with an increased disease severity in patients with Coronavirus Disease 2019 (COVID-19): a pooled analysis of published literature. Int J Stroke 2020; 15: 385-9.

20. Moher D, Liberati A, Tetzlaff J, Altman DG. Preferred reporting items for systematic reviews and meta-analyses: the PRISMA statement. PLoS Med 2009; 6: e1000097.

21. de Almeida-Pititto B, Dualib PM, Zajdenverg L, et al. Severity and mortality of COVID 19 in patients with 
diabetes, hypertension and cardiovascular disease: a meta-analysis. Diabetol Metabol Syndr 2020; 12: 75.

22. Luo L, Fu M, Li Y, et al. The potential association between common comorbidities and severity and mortality of coronavirus disease 2019: a pooled analysis. Clin Cardiol 2020; 43: 1478-93.

23. Kumar A, Arora A, Sharma P, et al. Is diabetes mellitus associated with mortality and severity of COVID-19? A meta-analysis. Diabetes Metab Syndr 2020; 14: 535-45.

24. Huang I, Lim MA, Pranata R. Diabetes mellitus is associated with increased mortality and severity of disease in COVID-19 pneumonia - a systematic review, meta-analysis, and meta-regression. Diabetes Metab Syndr 2020; 14: 395-403.

25. Del Sole F, Farcomeni A, Loffredo L, Carnevale R, Menichelli D. Features of severe COVID-19: a systematic review and meta-analysis. Eur J Clin Invest 2020; 50: e13378.

26. Pranata R, Huang I, Lim MA, Wahjoepramono EJ, July J. Impact of cerebrovascular and cardiovascular diseases on mortality and severity of COVID-19-systematic review, meta-analysis, and meta-regression. Eur J Clin Investig 2020; 29: 104949.

27. Popov GT, Baymakova M, Vaseva V, Kundurzhiev T, Mutafchiyski V. Clinical characteristics of hospitalized patients with COVID-19 in Sofia, Bulgaria. Vector Borne Zoonotic Dis 2020; 20: 910-5.

28. Wei $Y$, Zeng $W$, Huang $X$, et al. Clinical characteristics of 276 hospitalized patients with coronavirus disease 2019 in Zengdu District, Hubei Province: a single-center descriptive study. Obesity 2020; 20: 549.

29. COVID-19Statements \& Official Documents 2020. Available from: https://www.thoracic.org/covid/covid19statements.php.

30. Yu X, Sun X, Cui P, et al. Epidemiological and clinical characteristics of 333 confirmed cases with coronavirus disease 2019 in Shanghai, China. Transbound Emerg Dis 2020; 67: 1697-707.

31. Wang D, Hu B, Hu C, et al. Clinical characteristics of 138 hospitalized patients with 2019 novel coronavirus-infected pneumonia in Wuhan, China. JAMA 2020; 323: 1061-9.

32. Al Kuwari HM, Abdul Rahim HF, Abu-Raddad LJ. Epidemiological investigation of the first 5685 cases of SARS-CoV-2 infection in Qatar, 28 February-18 April 2020. BMJ Open 2020; 10: e040428.

33. Shabrawishi M, Al-Gethamy MM, Naser AY, et al. Clinical, radiological and therapeutic characteristics of patients with COVID-19 in Saudi Arabia. PLoS One 2020; 15: e0237130.

34. Aromataris E MZ. JBI Manual for Evidence Synthesis 2020.

35. Study Quality Assessment Tools 2020. Available from: https://www.nhlbi.nih.gov/health-topics/study-quality-assessment-tools.

36. Balduzzi S, Rücker G. How to perform a meta-analysis with R: a practical tutorial. Evid Based Ment Health 2019; 22: 153-60.

37. Higgins JPT, Thompson SG, Deeks JJ, Altman DG. Measuring inconsistency in meta-analyses. BMJ 2003; 327: 557-60.

38. World Medical Association Declaration of Helsinki: ethical principles for medical research involving human subjects. JAMA 2013; 310: 2191-4.

39. Shahriarirad R, Khodamoradi Z, Erfani A, et al. Epidemiological and clinical features of 2019 novel coronavirus diseases (COVID-19) in the South of Iran. BMC Infect Dis 2020; 20: 427.
40. Qin C, Zhou L, Hu Z, et al. Dysregulation of immune response in patients with coronavirus 2019 (COVID-19) in Wuhan, China. Radiology 2020; 71: 762-8.

41. Peng Y, Meng K, He M, et al. Clinical characteristics and prognosis of 244 cardiovascular patients suffering from coronavirus disease in Wuhan, China. BMJ Open 2020; 9: e016796.

42. Mao L, Jin H, Wang M, et al. Neurologic manifestations of hospitalized patients with coronavirus disease 2019 in Wuhan, China. J Am Heart Assoc 2020; 77: 683-90.

43. Li K, Wu J, Wu F, et al. The clinical and chest CT features associated with severe and critical COVID-19 pneumonia. Investig Radiol 2020; 55: 327-31.

44. Lee JY, Hong SW, Hyun M, et al. Epidemiological and clinical characteristics of coronavirus disease 2019 in Daegu, South Korea. J Korean Med Sci 2020; 98: 462-6.

45. Ji W, Huh K. Effect of underlying comorbidities on the infection and severity of COVID-19 in Korea: a nationwide case-control study. J Korean Med Sci 2020; 35: e237.

46. Huang R, Zhu L. Clinical findings of patients with coronavirus disease 2019 in Jiangsu province, China: a retrospective, multi-center study. PLoS Negl trop Dis 2020; 14: e0008280.

47. Bhargava A, Fukushima EA, Levine $M$, et al. Predictors for severe COVID-19 infection. Clin Infect Dis 2020; 71 : 1962-8.

48. Buckner FS, McCulloch DJ, Atluri V, et al. Clinical features and outcomes of 105 hospitalized patients with covid-19 in Seattle, Washington. Clin Infect Dis 2020; 71: 2167-73.

49. Cai Q, Huang D, Ou P, et al. COVID-19 in a designated infectious diseases hospital outside Hubei Province, China. Allergy 2020; 75: 1742-52.

50. Cao Z, Li T, Liang L, et al. Clinical characteristics of Coronavirus disease 2019 patients in Beijing, China. PLoS One 2020; 15: e0234764.

51. Chen C, Chen C, Yan JT, Zhou N, Zhao JP, Wang DW. Analysis of myocardial injury in patients with COVID-19 and association between concomitant cardiovascular diseases and severity of COVID-19. Zhonghua Xin Xue Guan Bing Za Zhi 2020; 48: 567-71.

52. Chen Q, Zheng Z, Zhang C, et al. Clinical characteristics of 145 patients with corona virus disease 2019 (COVID-19) in Taizhou, Zhejiang, China. Infection 2020; 48: 543-51.

53. Chen X, Zheng F, Qing Y, et al. Epidemiological and clinical features of 291 cases with coronavirus disease 2019 in areas adjacent to Hubei, China: a double-center observational study. medRxiv 2020: 2020.03.03.20030353.

54. Colaneri M, Sacchi P, Zuccaro V, et al. Clinical characteristics of coronavirus disease (COVID-19) early findings from a teaching hospital in Pavia, North Italy, 21 to 28 February 2020. Infection 2020; 25: 2000460.

55. El Aidaoui K, Haoudar A, Khalis M, et al. Predictors of severity in Covid-19 patients in Casablanca, Morocco. BMJ Open 2020; 12: e10716.

56. Gao Y, Li T, Han M, et al. Diagnostic utility of clinical laboratory data determinations for patients with the severe COVID-19. J Med Virol 2020; 92: 791-6.

57. Guan WJ. Clinical characteristics of coronavirus disease 2019 in China. J Med Virol 2020; 382: 1708-20.

58. Hu L, Chen S, Fu Y, et al. Risk factors associated with clinical outcomes in 323 COVID-19 hospitalized patients in Wuhan, China. Clin Infect Dis 2020; 71: 2089-98.

59. Huang H, Song B, Xu Z, et al. Predictors of coronavirus disease 2019 severity: a retrospective study of 64 cases. Japan J Infect Dis 2021; 74: 54-60. 
60. Li, Ling Y, Zhang J, et al. Clinical characteristics of SARS-coV-2 infections involving 325 hospitalized patients outside Wuhan. Research Square 2020. DOI: 10.21203/rs.3.rs-18699/v1.

61. Li T, Lu L, Zhang W, et al. Clinical characteristics of 312 hospitalized older patients with COVID-19 in Wuhan, China. Arch Gerontol Geriatrics 2020; 91: 104185.

62. Li X, Xu S, Yu M, et al. Risk factors for severity and mortality in adult COVID-19 inpatients in Wuhan. J Allergy Clin Immunol 2020; 146: 110-8.

63. Liu D, Cui P, Zeng S, et al. Risk factors for developing into critical COVID-19 patients in Wuhan, China: a multicenter, retrospective, cohort study. EClinicalMedicine 2020; 25: 100471

64. Liu S, Luo H, Wang Y, et al. Clinical characteristics and risk factors of patients with severe COVID-19 in Jiang su province, China: a retrospective multicentre cohort study. BMC INfect Dis 2020; 20: 584.

65. Liu W, Tao ZW, Wang L, et al. Analysis of factors associated with disease outcomes in hospitalized patients with 2019 novel coronavirus disease. Chinese Med J 2020; 133: 1032-8.

66. Matsunaga N, Hayakawa K, Terada M, et al. Clinical epidemiology of hospitalized patients with COVID-19 in Japan: report of the COVID-19 REGISTRY JAPAN. Clin Infect Dis 2020. doi: 10.1093/cid/ciaa1470.

67. Schalekamp S, Huisman M, van Dijk R, et al. Model-based prediction of critical illness in hospitalized patients with COVID-19. Radiology 2021; 298: E46-54.

68. Zhu Z, Cai T, Fan L, et al. Clinical value of immune-inflammatory parameters to assess the severity of coronavirus disease 2019. Allergy 2020; 95: 332-9.

69. Zheng F, Tang W, Li H, Huang YX, Xie YL, Zhou ZG. Clinical characteristics of 161 cases of corona virus disease 2019 (COVID-19) in Changsha. BMJ 2020; 24: 3404-10.

70. Zheng S, Fan J, Yu F, et al. Viral load dynamics and disease severity in patients infected with SARS-CoV-2 in Zhejiang province, China, January-March 2020: retrospective cohort study. BMJ 2020; 369: m1443.

71. Zhao W, Yu S, Zha X, et al. Clinical characteristics and durations of hospitalized patients with COVID-19 in Beijing: a retrospective cohort study. medRxiv 2020: 2020.03.13.20035436

72. Zhao XY, Xu XX, Yin HS, et al. Clinical characteristics of patients with 2019 coronavirus disease in a non-Wuhan area of Hubei Province, China: a retrospective study. BMC Infect Dis 2020; 20: 311.

73. Zhang JJ, Dong $X$, Cao YY, et al. Clinical characteristics of 140 patients infected with SARS-CoV-2 in Wuhan, China. Allergy 2020; 75: 1730-41.

74. Zhang G, Hu C, Luo L, et al. Clinical features and shortterm outcomes of 221 patients with COVID-19 in Wuhan, China. J Clin Virol 2020; 127: 104364

75. Yu C, Lei Q, Li W, Wang X, Li W, Liu W. Epidemiological and clinical characteristics of 1663 hospitalized patients infected with COVID-19 in Wuhan, China: a single-center experience. J Infect Public Health 2020; 13: 1202-9.

76. Ye C, Zhang S, Zhang X, et al. Impact of comorbidities on patients with COVID-19: a large retrospective study in Zhejiang, China. J Med Virol 2020; 92: 2821-9.

77. Yao $\mathrm{Q}$, Wang $\mathrm{P}$, Wang $\mathrm{X}$, et al. A retrospective study of risk factors for severe acute respiratory syndrome coronavirus 2 infections in hospitalized adult patients. Pol Arch Intern Med 2020; 130: 390-9.

78. Xiang T, Liu J, Xu F, et al. Analysis of clinical characteristics of 49 patients with coronavirus disease 2019 in Jiangxi. Chinese J Respir Crit Care Med 2020; 19: 154-60.

79. Wang Z, Yang B, Li Q, Wen L, Zhang R. Clinical features of 69 cases with coronavirus disease 2019 in Wuhan, China. Clin Infect Dis 2020; 71: 769-77.

80. Wang Y, Liao B, Guo Y, et al. Clinical characteristics of patients infected with the novel 2019 coronavirus (SARS-Cov-2) in Guangzhou, China. Open Forum Infect Dis 2020; 7: ofaa187.

81. Wang W, Xin C, Xiong Z, et al. Clinical characteristics and outcomes of 421 patients with coronavirus disease 2019 treated in a Mobile Cabin Hospital. Chest 2020; 158: 939-46.

82. Wang D, Hu B, Hu C, et al. Clinical characteristics of 138 hospitalized patients with 2019 novel coronavirus-infected pneumonia in Wuhan, China. JAMA 2020; 323: 1061-9.

83. Wang B, Wang Z, Zhao J, et al. Epidemiological and clinical course of 483 patients with COVID-19 in Wuhan, China: a single-center, retrospective study from the mobile cabin hospital. Eur J Clin Microbiol Infect Dis 2020; 39: 2309-15.

84. Wan S, Xiang Y, Fang W, Zheng Y. Clinical features and treatment of COVID-19 patients in northeast Chongqing. Eur J Clin Microbiol Infect Dis 2020; 92: 797-806.

85. Shi Y, Yu X, Zhao H, Wang H, Zhao R, Sheng J. Host susceptibility to severe COVID-19 and establishment of a host risk score: findings of 487 cases outside Wuhan. Crit Care 2020; 24: 108.

86. Huang C, Wang Y, Li X, et al. Clinical features of patients infected with 2019 novel coronavirus in Wuhan, China. Lancet 2020; 395: 497-506.

87. Drummond GR, Vinh A, Guzik TJ, Sobey CG. Immune mechanisms of hypertension. Nat Rev Immunol 2019; 19: 517-32.

88. Milne S, Yang CX, Timens W, Bossé Y, Sin DD. SARSCoV-2 receptor <em>ACE2</em> gene expression and RAAS inhibitors. Lancet Respir Med 2020; 8: e50-e1.

89. Wang Y, Liu M, Gao J. Enhanced receptor binding of SARS-CoV-2 through networks of hydrogen-bonding and hydrophobic interactions. Proc Natl Acad Sci 2020; 117: 13967-74.

90. COVID-19 and Hypertension: What We Know and Don't Know 2020. Available from: https://www.acc. org/latest-in-cardiology/articles/2020/07/06/08/15/ covid-19-and-hypertension.

91. Mehta P, McAuley DF, Brown M, Sanchez E, Tattersall RS, Manson JJ. COVID-19: consider cytokine storm syndromes and immunosuppression. Lancet 2020; 395: 1033-4.

92. Barron E, Bakhai C, Kar P, et al. Associations of type 1 and type 2 diabetes with COVID-19-related mortality in England: a whole-population study. Lancet Diabetes Endocrinol 2020; 8: 813-22.

93. Wang X, Liu Z, Li J, et al. Impacts of type 2 diabetes on disease severity, therapeutic effect, and mortality of patients with COVID-19. J Clin Endocrinol Metab 2020; 105: dgaa535.

94. Visca D, Pignatti P, Spanevello A, Lucini E, La Rocca E. Relationship between diabetes and respiratory diseases - clinical and therapeutic aspects. Pharmacol Res 2018; 137: 230-5.

95. Toledo J, George L, Martinez E, et al. Relevance of non-communicable comorbidities for the development of the severe forms of dengue: a systematic literature review. PLoS Negl Trop Dis 2016; 10: e0004284.

96. Pouvreau C, Dayre A, Butkowski EG, de Jong B, Jelinek HF. Inflammation and oxidative stress markers in diabetes and hypertension. J Inflamm Res 2018; 11: 61-8. 
97. Odegaard JI, Chawla A. Connecting type 1 and type 2 diabetes through innate immunity. Cold Spring Harb Perspect Med 2012; 2: a007724.

98. Limonta D, Torres G, Capó V, Guzmán MG. Apoptosis, vascular leakage and increased risk of severe dengue in a type 2 diabetes mellitus patient. Diabetes Vasc Dis Res 2008; 5: 213-4.

99. Htun NS, Odermatt P, Eze IC, Boillat-Blanco N, D’Acremont V, Probst-Hensch N. Is diabetes a risk factor for a severe clinical presentation of dengue? Review and meta-analysis. PLoS Negl Trop Dis 2015; 9: e0003741.

100. Dooley KE, Chaisson RE. Tuberculosis and diabetes mellitus: convergence of two epidemics. Lancet Infect Dis 2009; 9: 737-46.

101. Dharmashankar K, Widlansky ME. Vascular endothelial function and hypertension: insights and directions. Curr Hypertens Rep 2010; 12: 448-55.

102. Papazafiropoulou A, Antonopoulos S. The COVID-19 pandemic and diabetes mellitus. Arch Med Sci Atheroscler Dis 2020; 5: 200-5.

103. Ramphul K, Joynauth J. An Update on the incidence and burden of diabetic ketoacidosis in the U.S. Diabetes Care 2020: dc201258.

104. Merkler AE, Parikh NS, Mir S, et al. Risk of ischemic stroke in patients with coronavirus disease 2019 (COVID-19) vs patients with influenza. JAMA Neurol 2020; 77: 1-7.

105. Fifi JT, Mocco J. COVID-19 related stroke in young individuals. Lancet Neurol 2020; 19: 713-5.

106. Lippi G, Favaloro EJ. D-dimer is associated with severity of coronavirus disease 2019: a pooled analysis. Thromb Haemostasis 2020; 120: 876-8.

107. Ellul MA, Benjamin L, Singh B, et al. Neurological associations of COVID-19. Lancet Neurol 2020; 19: 767-83.

108. How COVID-19 can damage the brain. Available from: https://www.nature.com/articles/d41586-020-02599-5.

109. Fang L, Karakiulakis G, Roth M. Are patients with hypertension and diabetes mellitus at increased risk for COVID-19 infection? Lancet Respir Med 2020; 8: e21.

110. Lo KB, McCullough PA, Rangaswami J. Antihypertensive drugs and risk of COVID-19? Lancet Respir Med 2020; 8: e29.

111. Nadar SK, Tayebjee MH, Stowasser M, Byrd JB. Managing hypertension during the COVID-19 pandemic. J Human Hypertens 2020; 34: 415-7.

112. Yang JK, Feng Y, Yuan MY, et al. Plasma glucose levels and diabetes are independent predictors for mortality and morbidity in patients with SARS. Diabetic Med 2006; 23: 623-8

113. Gheblawi M, Wang K, Viveiros A, et al. Angiotensin-converting enzyme 2: SARS-CoV-2 receptor and regulator of the renin-angiotensin system: celebrating the 20th anniversary of the discovery of ACE2. Circ Res 2020; 126: 1456-74.

114. de Abajo FJ, Rodríguez-Martín S, Lerma V, et al. Use of renin-angiotensin-aldosterone system inhibitors and risk of COVID-19 requiring admission to hospital: a case-population study. Lancet 2020; 395: 1705-14.

115. Alzahrani SS, Aleisa FK, Alghalbi JA, et al. Stroke management pathway during COVID-19 pandemic scientific statement by the Saudi Stroke Society. Nerosciences 2020; 25: 226-9.

116. Greene JG, Wright WL, Obideen M, Rangaraju S, Baracchini C, Pieroni A. Acute stroke management pathway during Coronavirus-19 pandemic. PLoS One 2020; 41: 1003-5.
117. Idowu AO, Wang Z, Yang Y, et al. COVID-19 associated ischemic stroke and hemorrhagic stroke: incidence, potential pathological mechanism, and management. Neurol Res Intern 2020; 11: 571996.

118. Jillella DV, Janocko NJ, Nahab F, Benameur K. Ischemic stroke in COVID-19: an urgent need for early identification and management. PLoS One 2020; 15: e0239443.

119. Leira EC. Preserving stroke care during the COVID-19 pandemic: potential issues and solutions. Eur J Neurol 2020; 95: 124-33.

120. Ojo AS, Balogun SA. Acute ischemic stroke in COVID-19: putative mechanisms, clinical characteristics, and management. Neurol Res Int 2020; 2020: 7397480.

121. Qureshi Al, Abd-Allah F, Al-Senani F, et al. Management of acute ischemic stroke in patients with COVID-19 infection: report of an international panel. Int J Stroke 2020; 15: 540-54.

122. Leira EC, Russman AN, Biller J, et al. Preserving stroke care during the COVID-19 pandemic: potential issues and solutions. Neurology 2020; 95: 124-33.

123. Sylaja PN, Srivastava MVP, Shah S, et al. The SARSCoV-2/COVID-19 pandemic and challenges in stroke care in India. Neurology 2020; 1473: 3-10.

124. Viaro F, Cianci V, Cattelan AM, et al. Stroke care during the COVID-19 pandemic: experience from three large European countries. Neurol Sci 2020; 27: 1794-800. 